\title{
PEMANFAATAN TEKNOLOGI INFORMASI DALAM PENGEMBANGAN PEMASARAN IKAN ASIN DI DESA UMBUL TANJUNG KECAMATAN CINANGKA
}

\author{
Hartadi Wijaya \\ Universitas Banten Jaya, Jl Syech Nawawi Albantani Serang, Banten, Indonesia \\ Email: wijayahartadi@gmail.com
}

\begin{abstract}
The aim of the Community Service Program in Real-Learning Education and Community Empowerment (KKNPPM) is to increase sales of the Umbul Tanjung village community, Cinangka District. The partners of this activity are the people of Umbul Tanjung Village, Cinangka District who have businesses or do not have their own businesses. Villagers who work as fishermen and locations to market their products are limited to the background of students to be able to help increase sales of their products including salted fish sales. The method of carrying out this service is through (1) Surveying through observation, interviews, and analysis of village considerations and potentials, (2) Training on account creation at the bukalapan or tokopedia sites. The results of this program add to people's knowledge and skills regarding (1) Utilization of Information Technology, and (2) selling salted fish in attractive packaging. This program is expected to facilitate the community in increasing their knowledge and skills in processing salted fish so that it is hygienic.
\end{abstract}

Keywords: Information Technology, Sales, Salted Fish.

\begin{abstract}
ABSTRAK
Tujuan Program Pengabdian Masyarakat Kuliah Kerja Nyata-Pembelajaran dan Pemberdayaan Kepada Masyarakat (KKN-PPM) adalah untuk meningkatkan penjualan masyarakat desa Umbul Tanjung, Kecamatan Cinangka. Mitra dari kegiatan ini adalah masyarakat desa Umbul Tanjung, Kecamatan Cinangka yang sudah memiliki usaha ataupun yang belum memiliki usaha sendiri. Masyarakat desa yang bekerja sebagai nelayan serta lokasi untuk memasarkan produknya yang terbatas melatar belakangi Mahasiswa untuk dapat membantu dalam meningkatkan penjualan produk mereka khususnya penjualan ikan asin. Metode pelaksanaan pengabdian ini yaitu melalui (1) Survey melalui pengamatan, wawancara, dan analisis permasalahan dan potensi desa, (2) Pelatihan pembuatan akun pada situs bukalapan ataupun tokopedia. Hasil dari program ini adalah bertambahnya pengetahuan dan keterampilan masyarakat mengenai (1) Pemanfaatan Teknologi Informasi, dan (2) menjual ikan asin dengan packaging yang menarik. Program ini diharapkan dapat memfasilitasi masyarakat dalam meningkatkan pengetahuan dan keterampilan dalam mengolah ikan asin agar hygenis.
\end{abstract}

Kata Kunci: Teknologi Informasi, Penjualan, Ikan Asin

\section{PENDAHULUAN}

Desa adalah Kesatuan masyarakat hukum yang mempunyai batas batas wiilayah, yang memiliki kewenangan untuk mengatur dan mengurus pemerintahan dan kepentingan masyarakat setempat berdasarkan hak asal usul,adat istiadat yang diakui dalam sistim pemerintahan nasional dan berada di daerah kabupaten. Umbul Tanjung adalah Desa yang terdiri dari beberapa Kampung. Desa Umbul Tanjung pada mulanya yaitu sebelum pada tahun 1969 Desa Umbul Tanjung Distrik Cinangka 
Keresidenan Banten, Jumlah penduduk desa Umbul Tanjung 1.510 Kepala Keluarga, terdiri dari lakilaki 2.865 Orang dan perempuan 2.429 Orang.

Desa Umbul Tanjung pada tahun 1974 dijabat oleh Kepala Desa diadakan pemilihan Kepala Desa dan yang dipercaya untuk menjabat sebagai kepala Desa adalah yang selanjutnya dijabat oleh PJS Yahya (1974-1980) Pada Tahun 1980-1990 Dijabat Oleh Sidik, pada tahun 1991 digantikan oleh H. Rakhmat sampai dengan tahun 1997. Pada tahun 1998 PILKADES Abdul Rokhman menjabat kepala Desa sampai tahun 2013 berturut-turut, Desa Umbul Tanjung belum berkembang dengan Kepala Desa. Lalu pada tahun 2013 digantikan oleh Kutbi. Pada tahun 2018 Kepala Desa di jabat sementara oleh PJ. Jumed sampai tahun ini.

Potensi Sumber Daya, Ekonomi, Seni Budaya Dan Pariwisata yaitu Sumber Daya Saluran air di Desa Umbul Tanjung kurang lancer sepanjang 600m, terputusnya beberapa saluran air di kampung bedahan s/d tanjung sepanjang 1500m. Di sektor Petanian, petani kecil di Desa Umbul Tanjung kekurangan modal tani sebanyak 23 Poktan. Petani padi dan palawija di Desa Rancasanggal butuh bantuan benih, pupuk dan obat-obatan untuk 23 Poktan sebanyak 1 paket. Kelompok tani di Desa Umbul Tanjung butuh bantuan traktor sebanyak 25 unit. Para Petani butuh penyuluh pertanian sebanyak 5 orang.

Di sektor perternakan bagi RTM Desa Umbultanjung perlu penambahan asset berupa bantuan ternak Kerbau dan kambing sebanyak 1000 ekor. Kurangnya tenaga medis kesehatan di Desa Umbultanjung sebanyak 5 orang. Menambahan kegiatan masyarakat dengan potensi yang ada perlu adnya bantuan bibit ikan air tawar Lele Dan Nila sebanyak 50.000 ekor. Sektor Perdagangan Pedang kecil kurang modal di Desa Umbul tanjung. Pengrajin Golok dan Anyaman kurang Modal.

Bidang Sosial Budaya didikan anak-Anak sekolah bagi RTM butuh bantuan peralatan sekolah sebanyak 300 anak. Menumbuhkan bakat dan seni perlu bantuan alat seni REBANA sebanyak 7 set. Seperangkat Alat Gendang Penca sebanyak 3 unit. Kurang sarana Majlis ta,lim diwilayah RW 05,07 sebanyak 3 unit. Mensejahterakan masyarakat RTM Desa perlu bantuan rehap rumah kumuh sebanyak 350 rumah. Masyarakat Desa butuh bantuan sunatan masal. Di desa Umbul tanjung obyek wisata alam yaitu wisata pantai wara - wiri. Obyek wisata ini terletak di Wilayah pangkuan desa Umbul Tanjung. Jarak dari Kampung Pasauran 1 sekitar 100 m.

\section{METODE}

Metode yang digunakan untuk mengumpulkan data laporan KKM ialah melalui wawancara, observasi, anjangsana, serta dokumentasi dari desa / kelurahan. Bahan yang diperlukan yaitu pelastik pembungkus untuk ikan asin, serta komputer / leptop sebagai penunjang dalam pemasaran ikan asin. Dalam melaksanakan kegiatan KKM kelompok, kami merancang dan membuat rencana program kemudian dibuat dalam suatu sistematika program kerja yang tererinci berdasarkan bidang kegiatan 
yang kami pilih. Ada beberapa bidang kegiatan kelompok yang kita pilih dalam program kerja KKM di Desa Umbul Tanjung adalah sosialisasi dan penyuluhan pemanfaatan teknologi dan gerakan sosial. Kegiatan ini memiliki maksud dan tujuan untuk mengenalkan pemasaran ikan asin melalui media teknologi informasi dan nengajak masyarakat agar lebih rukun antara satu dengan yang lainnya. Sasaran yang ingin dicapai dalam kegiatan ini adalah agar pemasaran produk ikan asin tersebut bisa di kenal secara luas

\section{Proses Pembuatan Ikan Asin}

Menurut (Riansyah et al., 2013) Pembuatan ikan asin kering merupakan yang paling sederhana. Ikan asin kering merupakan produk ikan yang cukup mudah dalam pembuatannya. Jeroan dan sisik ikan dibuang, kemudian dijemur atau dikeringkan dengan alat pengering. Menurut (Imbir et al., 2015) Proses pengolahan dan pengawetan ikan merupakan salah satu bagian penting dari mata rantai industri perikanan. Tanpa adanya kedua proses tersebut, peningkatan produksi ikan yang telah dicapai selama ini akan sia-sia, karena tidak semua produk perikanan dapat dimanfaatkan oleh kosumen dalam keadaan baik. Pengawetan ikan secara tradisional bertujuan untuk mengurangi kadar air dalam tubuh ikan, sehingga tidak memberikan kesempatan bagi bakteri untuk berkembang biak. Untuk mendapatkan hasil awetan yang bermutu tinggi diperlukan perlakuan yang baik selama proses pengawetan seperti, menjaga kebersihan bahan dan alat yang digunakan, menggunakan ikan yang masih segar serta garam yang bersih.

Menurut Permenkes RI No 33 tahun 2012 dikutip dari (Ernawati et al., 2017) Formalin merupakan bahan pengawet yang dilarang digunakan pada makanan. Formalin adalah nama dagang dari campuran formaldehid, metanol dan air. Pada suhu ruangan formalin adalah gas yang tidak berwarna, berbau tajam dan menyengat. Formalin sangat reaktif, mudah mengalami polimerisasi, dan dapat membentuk ledakan campuran di udara. Formalin adalah molekul yang sangat reaktif yang dapat secara langsung mengiritasi jaringan ketika terjadi kontak. Penggunaan formalin sebagai pengawet makanan semakin banyak dilakukan oleh para pelaku bisnis yang tidak bertanggung jawab.

Rasa ikan asin yang lezat berdasarkan cara pembuatannya. Ikan yang dipilih haruslah segar dan higienis. Harus adanya komposisi antar garam dan besar kecilnya ikan merupakan hal yang harus dicermati saat membuat ikan asin yang enak dan berkualitas. Penggaraman kering pada ikan yang memiliki ukuran besar pada waktu membuatnya dengan cara penyiangan dan pembelahan, misalnya ikan gabus, ikan tenggiri, ikan tongkol, ikan pari, ikan jambal, dan ikan cucut. Setelah penggaraman cukup ikan diangkat dan dibilas dengan air, lalu dijemur. Menurut (Moeljanto, 1992) beberapa faktor yang mempengaruhi kecepatan penetrasi garam ke dalam tubuh ikan, selain tingkat kemurnian garam yang digunakan, yaitu sebagai berikut : 


\section{Kadar lemak ikan}

Semakin tinggi kadar lemak yang terdapat di dalam tubuh ikan semakin lambat proses penetrasi garam ke dalam tubuh ikan.

\section{Ketebalan daging ikan}

Semakin tebal daging ikan semakin lambat proses penetrasi garam dan semakin banyak pula jumlah garam yang diperlukan.

\section{Kesegaran ikan}

Pada ikan yang memiliki kesegaran rendah, proses penetrasi garam berlangsung lebih cepat karena ikan dengan tingkat kesegaran rendah mempunyai tubuh yang relatif lunak, cairan tubuh tidak terikat dengan kuat dan mudah terisap oleh larutan garam yang mempunyai konsentrasi lebih tinggi. Apabila ikan kurang segar, produk ikan asin yang dihasilkan akan terlalu asin dan kaku

\section{Temperatur ikan}

Semakin tinggi temperatur tubuh ikan semakin cepat pula proses penetrasi garam ke dalam tubuh ikan. Tetapi sangat disayangkan, bahwa hal tersebut diikuti oleh perkembangan bakteri yang juga semakin cepat. Oleh karena itu, sebelum dilakukan proses penggaraman sebaiknya ikan ditangani lebih dahulu dengan baik agar sebagian besar bakteri yang dikandung dapat dihilangkan.

\section{Konsentrasi larutan garam}

Semakin tinggi perbedaan konsentrasi antara garam dengan cairan yang terdapat dalam tubuh ikan, semakin cepat proses penetrasi garam ke dalam tubuh ikan. Selain itu, proses penetrasi garam akan menjadi lebih cepat lagi apabila digunakan garam kristal. Semakin tinggi konsentrasi garam, semakin tinggi daya awet ikan tetapi ikan menjadi semakin asin dan kurang disukai. Berikut ini cara pengolahan ikan asin:

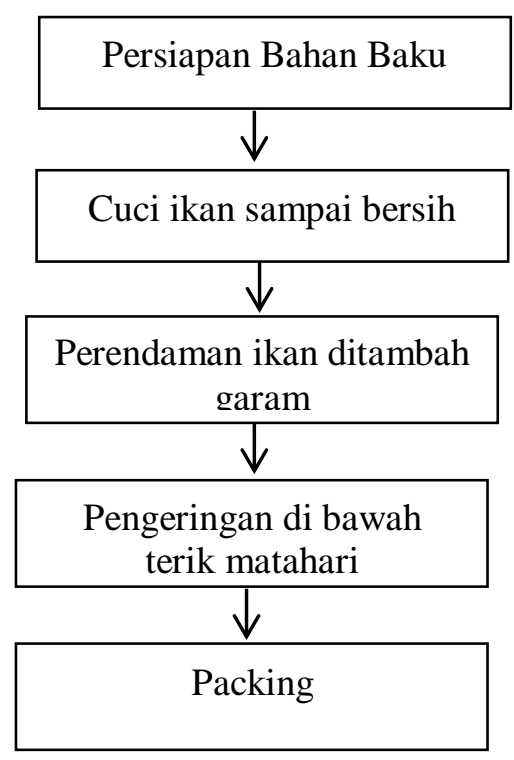

Diagram 1. Proses Pengolahan Ikan Asin 
Penggaraman dilakukan dengan 3 cara, yaitu penggaraman kering (dry salting), penggaraman basah (wet salting), kench salting.

1. Penggaraman kering (dry salting)

Pada penggaraman kering ikan yang digunakan bisa ukuran besar maupun kecil. Dengan cara ikan yang akan diolah ditaburi garam lalu disusun secara berlapis-lapis.Setiap lapisan ikan diselingi oleh lapisan garam.

2. Penggaraman basah (wet salting)

Dengan menggunakan larutan garam sebagai media untuk merendam ikan.

3. Penggaraman kench salting

Penggaraman ini dengan menggunakan kedap air. Ikan ditumpuk di atas lantai atau menggunakan keranjang.

\section{HASIL DAN PEMBAHASAN}

1. Hasil yang dicapai dan Tindak Lanjut

1) Sosialisasi dan Penyuluhan

Kegiatan sosialisasi dan penyuluhan yang telah dilakukan yaitu masyarakat desa umbul tanjung sangat antusias mengikuti acara ini mulai dari nelayan, para pemuda dan warga pembuat ikan asin. Tindak lanjut dari kegiatan ini yaitu masyarakat umbul tanjung terutama pengelola pengelola ikan asin yang ada di Desa umbul tanjung, dapat meningkatkan pemasaran ikan asin seacara luas menggunakan media teknologi informasi.

2) Pembuatan Website

Pembuatan website ini merupakan salah satu program yang berbasis teknologi. Dimana dalam program ini memanfaatkan website atau Sosial media untuk memberi informasi tentang desa Umbul Tanjung kepada masyarakat luas. Hasil yang dicapai dalam kegiatan ini adalah informasi pihak balai desa atau yang mengelola website ini dapat terus memberikan informasi kepada masyarakat mengenai perkembangan Desa Umbul Tanjung. Tindak lanjut dari kegiatan ini yaitu pengelola website dapat terus mengupdate informasi - informasi yang berkaitan dengan Desa Umbul Tanjung, sehingga Desa Umbul Tanjung dapat dikenal oleh masyarakat luas. 
2. Partisipasi Masyarakat dan Peran serta Pemda/Dinas/Instansi

Tabel 1. Peserta Kegiatan

\begin{tabular}{|c|l|ll|}
\hline No & \multicolumn{1}{|c|}{ Kegiatan } & \multicolumn{1}{c|}{ Nama Instansi } \\
\hline 1 & Sosialisasi dan Penyuluhan & 1. Ibu-ibu PKK \\
& & 2. Pemerintah Desa \\
& & 3. GEBAS (Gerakan Barisan Sosial) \\
\hline
\end{tabular}
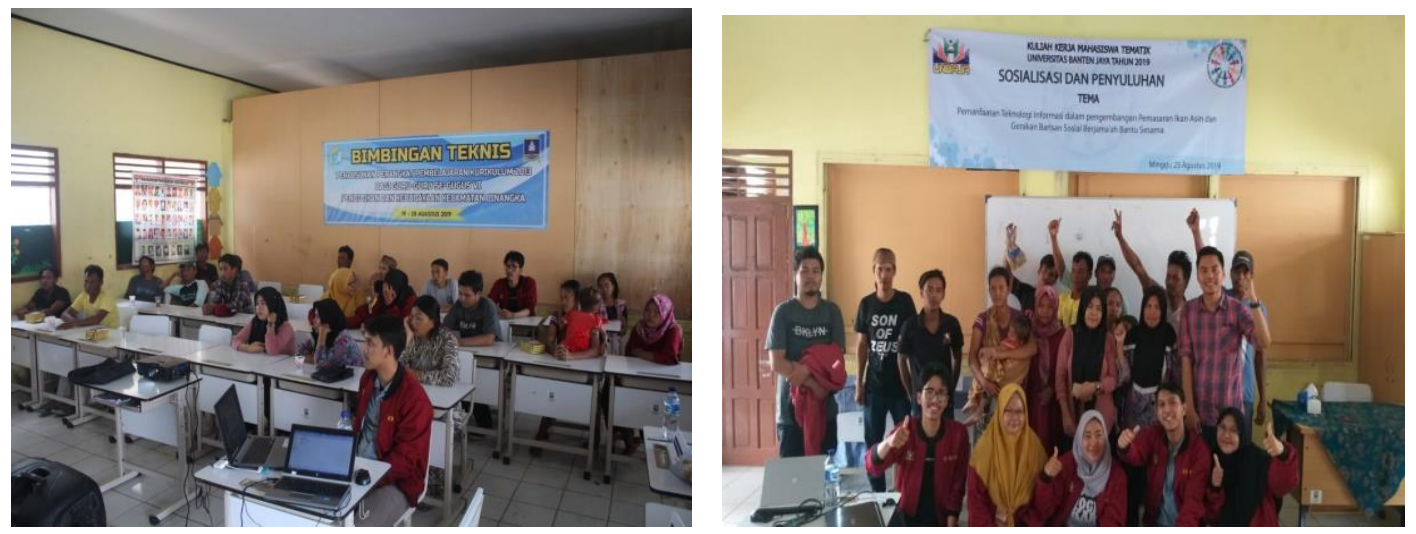

\section{Gambar 1. Sosialisasi Masyarakat Desa Umbul Tanjung}
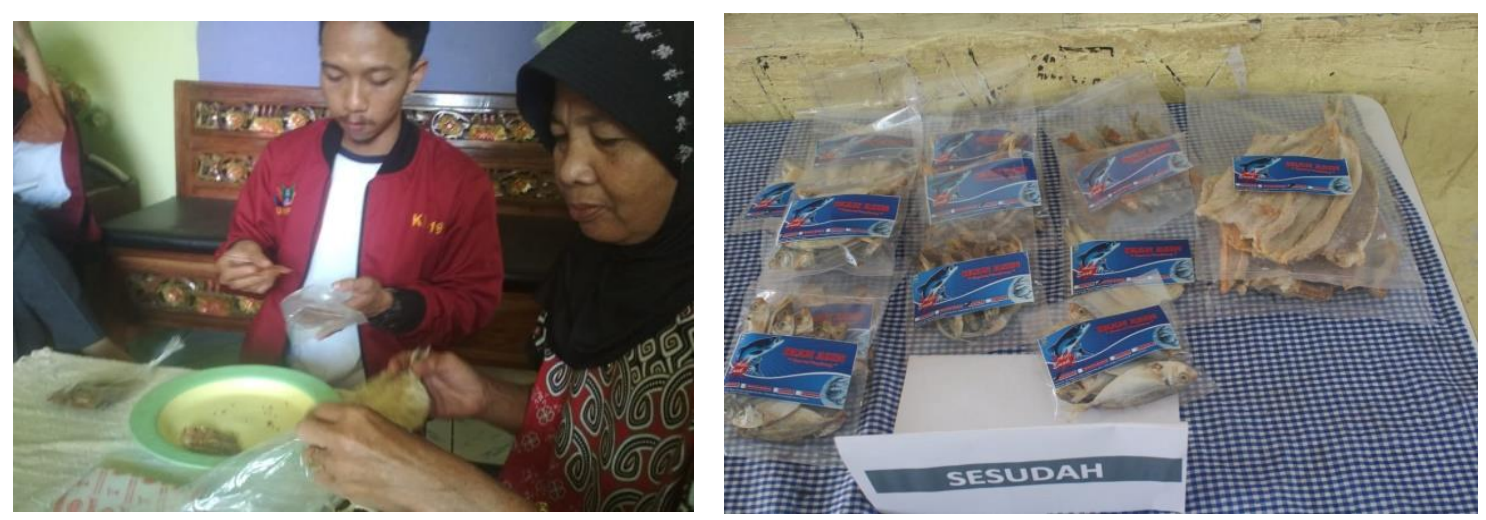

Gambar 2. Proses Packing Ikan Asin

\section{SIMPULAN}

Dari uraian yang telah kami paparkan di atas tentang serangkaian kegiatan kami selama KKM. Ada hal-hal yang dapat dijadikan kesimpulan di antaranya, KKM merupakan salah satu bentuk pengabdian kami kepada masyarakat yang eksistensinya masih sangat dibutuhkan oleh masyarakat. Hal ini dapat terlihat ketika kami sampai di tempat lokasi kami melaksanakan kegiatan KKM. Masyarakat dengan antusias menyambut kedatangan tim KKM. Aura yang menampakkan harapan 
tersorot dari wajah mereka. Persepsi "KKM akan membangun Desa" menjadikan mereka bergantung dengan program-pogram yang akan dilaksanakan.

Berbagai masukan, pandangan dan harapan mereka sampaikan demi kemajuan Desa. Di mana fokus yang diharapkan oleh masyarakat adalah terciptanya kemajuan Desa. Terutama dalam hal pendidikan dan ahlakul karimah yang sangat erat hubunganya dengan bidang keagamaaan. Dalam pelaksanaan program kerja, kami tidak terpancang pada kegiatan yang sifatnya global, artinya sifat supel dengan mempertimbangkan berbagai faktor di lapangan. Serta dengan mempertimbangkan kemampuan Kelompok 13 KKM UNBAJA baik dari segi materi maupun non materi. Dan yang menjadi fokus kegiatan kami adalah kegiatan yang sifatnya krusial, penting dan sangat dibutuhkan oleh masyarakat, baik dapat dirasakan secara langsung maupun tidak langsung. Hal inilah yang menjadikan dasar pijakan Kelompok kami dalam merealisasikan program kerja yang telah diputuskan secara bersama-sama.

KKM yang terkesan sebagai kegiatan sampingan ternyata memiliki arti penting yang bisa ditawarkan. Inti kegiatan KKM yang merupakan Pengabdian terhadap masyarakat kerap kali dipertanyakan fungsionalnya. Tapi tidak bisa dipungkiri bahwa KKM masih dibutuhkan oleh masyarakat yang berada dalam kategori desa binaan.Satu contoh Desa Umbul Tanjung yang masih perlu dirambah agar di dalamnya tercipta warga yang kreatif, inovatif dalam beraktifitas. Melalui KKM dirasa mampu mewujudkan simbiosis mutualisme antara mahasiswa selaku subyek KKM dan Masyarakat selaku obyek KKM. Meski begitu, perlu adanya perubahan format KKM yang distandarkan dengan efisiensi kegiatan.

Kami Kelompok 13 KKM UNBAJA mencoba membuang image kami selaku mahasiswa dengan berusaha memainkan peran kami selaku the agent of social change. Sehingga masyarakat benar-benar merasakan kontribusi KKM secara nyata.

\section{UCAPAN TERIMA KASIH}

Ucapan terimakasih disampaikan kepada

1. Direktorat Riset dan Pengabdian Masyarakat, Direktorat Jenderal Penguatan Riset dan Pengembangan, Kementerian Riset, Teknologi, dan Pendidikan Tinggi yang telah memberikan kesempatan dan dukungan untuk melaksanakan kegiatan Kuliah Kerja Nyata-Pembelajaran dan Pemberdayaan Kepada Masyarakat (KKN-PPM) dengan tema "Teknologi Informasi Desa, Upaya meningkatkan partisipasi dan keterampilan masyarakat dalam pembangunan desa (Pemanfaatan Teknologi Informasi Dalam Pengembangan Pemasaran Ikan Asin di Desa Umbul Tanjung, Kec. Cinangka) tahun pelaksanaan 2019"

2. Kepala Desa Umbul Tanjung yang telah bekerjasama dan memberikan kesempatan untuk dapat melakukan pengabdian di desa tersebut. 
3. Dosen Pembimbing Lapangan Universitas Banten Jaya yang telah bekerjasama dalam pelaksanaan kegiatan KKN-PPM

\section{DAFTAR PUSTAKA}

Ernawati, A., Pangestuti, D. R., \& Widajanti, L. (2017). Efektivitas Perendaman Air Hangat dan Air Garam terhadap Penurunan Kadar Formalin Ikan Teri Asin di Tingkat Pedagang Pasar Kota Semarang. Jurnal Kesehatan Masyarakat (e-Journal), 5(4), 613-621.

Imbir, E., Onibala, H., \& Pongoh, J. (2015). Studi pengeringan ikan layang (Decapterus sp) asin dengan penggunaan alat pengering surya. Media Teknologi Hasil Perikanan, 3(1).

Moeljanto. (1992). Pengawetan Dan Pengolahan Hasil Perikanan (1st ed.). Swadaya.

Riansyah, A., Supriadi, A., \& Nopianti, R. (2013). Pengaruh perbedaan suhu dan waktu pengeringan terhadap karakteristik ikan asin sepat siam (Trichogaster pectoralis) dengan menggunakan oven. Jurnal Fishtech, 2(1), 53-68. 